\title{
Identifying MSM-competent physicians in China: a national online cross-sectional survey among physicians who see male HIV/STI patients
}

Peipei Zhao ${ }^{1}$, Bolin Cao ${ }^{2}$, Cedric H. Bien-Gund ${ }^{3}$, Weiming Tang ${ }^{3,4}$, Jason J. Ong ${ }^{5,6}$, Yi Ding ${ }^{1}$, Weiying Chen ${ }^{1}$, Joseph D. Tucker ${ }^{3,4,5^{*}}$ and Zhenzhou Luo ${ }^{1 *}$

\begin{abstract}
Background: Men who have sex with men (MSM) are at high risk of human immunodeficiency virus (HIV) infection and sexually transmitted infection (STI) in China. Inadequate clinical services and poor clinical competency among physicians are major barriers to improving the sexual health of MSM. This study aims to understand physician clinical competency in providing MSM health services in China.

Methods: We conducted an online cross-sectional survey among Chinese physicians who have seen male patients for STI complaints in the past year. We obtained information on individual demographics, clinical practice, attitudes toward MSM, and interest in contributing to MSM clinical services. We defined an MSM-competent physician as one who asked male patients about sexual orientation, sexual practices, and recommended HIV/ STI testing during a clinic visit. We conducted multivariable logistic regression to identify factors associated with MSM competency.

Results: In total, 501 physicians completed the survey. The most common subspecialties were dermatovenereology (33.1\%), urology (30.1\%), and general medicine (14.4\%). Roughly half $(n=267,53.3 \%)$ reported seeing MSM in the past 12 months. Among physicians who saw MSM in the past 12 months, 60.3\% $(n=161)$ met criteria as MSM-competent physicians, and most ( $n=234,87.6 \%)$ MSM-competent physicians reported positive or neutral attitudes towards MSM. Over $60 \%$ of all physicians were willing to participate in activities for improving MSM services, such as training and being on a list of physicians willing to serve MSM. MSM-competent physicians showed no sociodemographic differences compared with non MSM-competent physicians. MSM-competent physicians were more willing to have their medical institution named on a public clinic list capable of serving MSM (aOR: 1.70, 95\%Cl: 1.01-2.86) and being on a public physician list capable of serving MSM (aOR: 1.77, 95\%Cl: 1.03-3.03).

Conclusions: MSM-competent physicians included a broad range of individuals that practiced in diverse clinical settings. Most physicians were interested in improving and expanding MSM clinical services, despite having neutral attitudes toward same-sex behavior. Future interventions should focus on developing MSM clinical competency and expanding services that meet the needs of MSM.
\end{abstract}

Keywords: Men who have sex with men, Clinical services, HIV care continuum, HIV/STI testing

\footnotetext{
* Correspondence: jdtucker@med.unc.edu; paulluo9909@163.com

${ }^{3}$ University of North Carolina Project-China, No. 2 Lujing Road, Guangzhou 510095, China

'Shenzhen Nanshan Center for Chronic Disease Control, Shenzhen, China

Full list of author information is available at the end of the article
}

(c) The Author(s). 2018 Open Access This article is distributed under the terms of the Creative Commons Attribution 4.0 International License (http://creativecommons.org/licenses/by/4.0/), which permits unrestricted use, distribution, and reproduction in any medium, provided you give appropriate credit to the original author(s) and the source, provide a link to the Creative Commons license, and indicate if changes were made. The Creative Commons Public Domain Dedication waiver (http://creativecommons.org/publicdomain/zero/1.0/) applies to the data made available in this article, unless otherwise stated. 


\section{Background}

Globally, men who have sex with men (MSM) are at elevated risk of HIV acquisition, other sexually transmitted infections (STIs), substance abuse, and mental health disorders [1-4]. In many low- and middle-income countries (LMICs), MSM face significant barriers to accessing health care $[5,6]$. MSM in LMICs report stigma, discrimination, and ignorance of health services as major barriers to health care provision [7, 8]. In addition, MSM have reported negative interactions with physicians, such as providers who did not ask or disapproved of same-sex practices, did not provide sexual health counseling or HIV/STI testing services, or revealed their sexual orientation to others [9].

HIV prevalence among MSM in China has increased from $6.0 \%$ in 2010 , to $8.0 \%$ in 2015 [10]. It was estimated that the lifetime HIV testing for MSM is $47 \%$, and that $18 \%$ of them didn't retrieve their results [11]. The infection risk of STIs was significantly higher in MSM compared to the general population [12]. The rapid spread of HIV and STIs among MSM has led to renewed efforts to improve health services for MSM [13]. However, Chinese policy towards MSM is ambiguous (no approval, no disapproval and no promotion) and same-sex marriage is illegal. In China, there is a lack of laws to protect MSM from discrimination and unfair treatment. Experienced and anticipated health discrimination is widely reported by MSM and is also a barrier for MSM to use health services (including HIV testing) in China [14, 15]. In one cross-sectional study of MSM in China, only $16.3 \%$ had disclosed their sexual orientation to any health care professional [16], lower than in high-income countries [17, 18]. Incompetent health care providers also delay the testing and services of HIV and STIs for MSM. Provider-initiated HIV testing services is an effective way to increase the uptake of HIV testing [19]. But in China, STI care providers offered HIV testing to only $28.4 \%$ of their patients [20]. In addition to providing HIV/STI testing services, physicians serving MSM are responsible for obtaining a thorough sexual history, discussing sexual practices, partners, and conducting an appropriate physical examination $[15,21]$. But these services were not common practice among Chinese physicians [20]. In qualitative studies, MSM in China have indicated the importance of knowledgeable, confidential, gay-friendly physicians in accessing sexual health services [22]. Furthermore, physicians need the material resources necessary to provide appropriate care for MSM, such as condoms, lubricants, and sexual health information for patients [23].

MSM-competent health services are seen as a key component in HIV and STI prevention programs, which offers MSM comprehensive sexual health services including health promotion, counselling, peer support, prevention, adequate diagnostics and treatment. It provides health care that is sensitive to the special needs of MSM and encourages them to obtain health care services and disclosure sexual orientation to health providers [24]. Health providers, including physicians and nurses, need education and training to be able to deliver competent services. However, there is a lack of competency training among China's health providers to provide more appropriate routine care and remove barriers for MSM to get appropriate services [20].

Physicians' clinical competency to serve MSM has been overlooked in HIV and STI prevention programs. In order to inform the development of MSM-competent clinical care, we conducted a survey among Chinese physicians who have provided STI care to men. Given that it is difficult to evaluate the physicians' competency in a comprehensive way, our study focused on their clinical behaviors. In this study, we adopted the definition of MSM-competent physicians from other original research as those who self-reported having asked their last male STI patient about sex with other men, anal sex, and recommended both HIV and syphilis testing [25]. We also assessed the physicians' workplace information, their attitudes towards MSM and their willingness in future training to explore factors that correlate with competency.

\section{Methods}

\section{Study design and participants}

We conducted a cross-sectional, nationwide online survey of physicians who had seen male STI patients in China in the past twelve months. Physicians were recruited through the Xingren medical mobile phone application (app), where licensed physicians can register as online physicians on the app. The app allows registered physicians to communicate with patients, manage cases, and share medical knowledge and experiences with other physicians. Verified physicians in the app can get paid from their online encounters with patients by providing medical advice to patients. App-based counseling typically involves obtaining a clinical history, but without providing physical examination.

The survey link with an invitation message was sent to a subset of Xingren verified physicians who registered in dermatovenereology, urology, proctology, internal medicine, pediatrics, infectious disease, and general practice specialties $(n=120,126)$. Based on the profile of the registered physicians in the app, they were located all over mainland China. Physicians were included from both hospitals and primary care centers. In order to be eligible for the survey, physicians needed to live in China, have used the app within the last six months, and have seen at least one male STI patient offline in the past 12 months. The physicians registered in the Xingren app all had practice licenses in China. Male STI patients were 
defined as those who were diagnosed with at least one type of STI or had symptoms of STIs when they saw physicians. STIs include HIV, syphilis, chlamydia, gonorrhoea, human papillomavirus, herpes, trichomonas, and mycoplasma [26].

We pre-specified the recruitment sample as 500 participants. Based on previous research in China [27] we recruited a sample size of 500 physicians. This sample size was also limited by funding constraints as we provided an incentive for physicians to participate. We implemented a recruitment strategy in two steps. First, we sent the participation link to physicians whose unique Xingren identification number ended in 1,2 , or $3(n=$ 6689). In order to meet the pre-specified sample size, we then sent the participation link to an additional 1400 physicians who were selected randomly from the rest of the eligible physicians. We used Randbetween function in Microsoft Excel to ensure that a random sample was invited. Physicians initiated the survey by clicking on the participation link. Participants were asked to sign an electronic consent form before they started the survey. We provided each participant with a small financial incentive for completion of the survey ( $\$ 4.50$ USD).

\section{Survey}

Eligible physicians completed a survey that included demographic and workplace information, clinical practice information, attitudes toward MSM, and interest in contributing to MSM clinic services.

\section{Demographic and workplace information}

We asked physicians their age, sex (male/female), highest educational degree (Associate/Bachelor/Master/ $\mathrm{PhD}$ ), and medical specialty. We also asked about the medical institution where physicians worked, including the level of care (primary, secondary or tertiary) and type of medical institution (public or private). The higher level of care means larger service coverage, more health functions and more medical practitioners. Higher level medical institution provided more comprehensive services. We asked for clinic information on medical equipment including the availability of proctoscopes or anoscopes (Yes/No), condoms and lubricants (Yes/No), and HIV/STI prevention pamphlets and educational materials (Yes/No).

\section{Clinical practice information}

Physicians were asked three items about their clinical practice during the last time they saw a male STI patient. These items included whether they asked about sex with other men, whether they asked about anal sex, and whether they recommended both HIV and syphilis testing. In this study, we defined MSM-competent physicians as those who self-reported having asked their last male STI patient about sex with other men, anal sex, and recommended both HIV and syphilis testing [25]. Although this is not a comprehensive benchmark for MSM clinical competence, it is consistent with previous literature on MSM health care [28-30]. In our analysis about MSM -competent physicians, we excluded those who have not seen MSM patients in the past 12 months.

\section{Attitudes toward MSM}

Physician attitudes toward MSM were measured by asking participants about their agreement with five statements. The 5-item scale was adapted from Herek's Attitudes Toward Lesbians and Gay Men Scale [31], which has been validated in China [32]. Cronbach's alpha value of the Chinese scale is 0.90 and confirmatory factor analysis demonstrates that it has good validity. The scale includes the following statements: "Male homosexuals are disgusting;" "Male homosexuality is a perversion;" "Homosexual behavior between two men is just plain wrong;" "Male homosexuality is merely a different kind of lifestyle that should not be condemned;" and "Homosexual should be segregated by society (residential segregation or occupational segregation)." The survey used a scale of 1 to 5 ( $1=$ strongly disagree; $2=$ disagree somewhat; $3=$ neither agree nor disagree; $4=$ agree somewhat; 5 = strongly agree).For each statement, 1 and 2 indicated positive attitudes; 3 indicate neutral attitudes; 4 and 5 indicate negative attitudes. Then items were summed to create a total score. Scores range from 5 (extremely positive attitude) to 25 (extremely negative attitude), with a value of 15 considered neutral. Those who scored less than 15 presented positive attitudes and more than 15 presented negative attitudes.

\section{Interest in contributing to MSM clinical services}

Physicians' interest in contributing to quality improvement programs for MSM clinical services were also measured with three items. Physicians were asked whether they were interested in having their medical institution named on a public clinic list capable of serving MSM. In addition, physicians were asked about being included on a public physician list capable of serving MSM. They were also asked if they were interested in obtaining further training focused on clinical services for MSM.

Statistical analysis IBM SPSS Statistics 19 was used for all analyses. Descriptive statistics were used to describe physicians' socio-demographic information, institutional information, interests in contributing to the MSM clinical services and attitudes towards MSM. The primary outcome of the study is MSM-competent physicians, defined by physicians' clinical practice with their last STI patients. Bivariate logistic regression was used to 
examine factors associated with being MSM-competent physicians. Demographic characteristics, workplace information, attitudes towards MSM and interested in contributing to MSM services are examined as independent variables. The results were reported as odds ratios (OR) with corresponding 95\% confidence intervals $(95 \% \mathrm{CI})$. Variables that were significant in the bivariate logistic regression were included in the multivariable analysis. In the multivariable logistic regression, we adjusted for demographic characteristics (age, sex, and education) and reported adjusted odds ratios (aOR). Statistical significance was determined at $P<0.05$ in the model.

\section{Results}

A total of 8089 physicians received the participation link, and 1556 physicians clicked the survey link and entered the survey, of which 699 provided informed consent. Among physicians who consented, 186 did not meet eligibility criteria, and another 12 surveys were invalidated due to insufficient information. A total of 501 physicians were included in the final analysis.

Demographic characteristics and institutional information On average, physicians in our survey were $37.6 \pm 8.2$ years old (Table 1). Three-quarters of them were male $(n=367,75.0 \%)$, and over half of the physicians had obtained a master's degree or higher $(n=276,53.3 \%)$. One third of physicians reported specialization in dermatovenerology $(n=166,33.1 \%)$, followed by urology $(n=151$, $30.1 \%)$, and internal medicine $(n=51,10.2 \%)$.

Almost two-thirds of the physicians worked in tertiary care hospitals $(n=322,64.3 \%)$ and $89.6 \%(n=449)$ worked in public medical institutions. Most physicians reported that proctoscopes or anoscopes were available in their medical facilities $(n=403,80.4 \%), 75.2 \%(n=377)$ reported STI prevention pamphlets or educational materials were available, and $51.9 \%(n=260)$ reported free condom and lubricants were available on site.

\section{Physician clinical practice}

In their last clinical encounter with a male STI patient, $75.4 \%(n=378)$ of physicians reported asking about sex with other men. Over half $(n=277,55.3 \%)$ asked about anal sex, and $90.8 \%(n=455)$ recommended both HIV and syphilis testing.

\section{Physician attitudes to MSM}

When presented with individual statements regarding MSM (Table 2), most physicians indicated they had neutral attitudes toward MSM. Nonetheless, the total scores of the scale showed most $(n=158,59.2 \%)$ physicians surveyed had a positive attitude towards MSM. Nearly a
Table 1 Demographic characteristics of physicians who saw at least one male STI patient, $2017(N=501)$

\begin{tabular}{|c|c|c|}
\hline \multirow[t]{2}{*}{ Characteristics } & \multicolumn{2}{|c|}{ Total } \\
\hline & $n$ & $\%$ \\
\hline Age (years) & \multicolumn{2}{|c|}{ Mean: 37.6 \pm 8.2; Min: 23; Max: 76} \\
\hline$\leq 30$ & 110 & $22.0 \%$ \\
\hline $31-40$ & 244 & $48.7 \%$ \\
\hline$>40$ & 147 & $29.3 \%$ \\
\hline \multicolumn{3}{|l|}{ Sex } \\
\hline Male & 376 & $75.0 \%$ \\
\hline Female & 125 & $25.0 \%$ \\
\hline \multicolumn{3}{|l|}{ Education } \\
\hline Associate's degree ${ }^{a}$ & 36 & $7.2 \%$ \\
\hline Bachelor's degree & 198 & $39.5 \%$ \\
\hline Master's degree & 216 & $43.1 \%$ \\
\hline $\mathrm{PhD}$ degree & 51 & $10.2 \%$ \\
\hline \multicolumn{3}{|l|}{ Specialty } \\
\hline Dermatovenerology & 166 & $33.1 \%$ \\
\hline Urology & 151 & $30.1 \%$ \\
\hline General medicine $^{b}$ & 72 & $14.4 \%$ \\
\hline Proctology & 41 & $8.2 \%$ \\
\hline Others $^{c}$ & 37 & $7.4 \%$ \\
\hline Infectious disease & 34 & $6.8 \%$ \\
\hline \multicolumn{3}{|l|}{ Level of care } \\
\hline Primary & 34 & $6.8 \%$ \\
\hline Secondary & 145 & $28.9 \%$ \\
\hline Tertiary & 322 & $64.3 \%$ \\
\hline \multicolumn{3}{|l|}{ Type of Medical institute } \\
\hline Public & 449 & $89.6 \%$ \\
\hline Private & 52 & $10.4 \%$ \\
\hline \multicolumn{3}{|c|}{ Proctoscope or anoscope available } \\
\hline Yes & 403 & $80.4 \%$ \\
\hline No & 98 & $19.6 \%$ \\
\hline
\end{tabular}

Free condom and lubricants available

$\begin{array}{lll}\text { Yes } & 260 & 51.9 \% \\ \text { No } & 241 & 48.1 \%\end{array}$

STI prevention pamphlets or educational materials available

$\begin{array}{lll}\text { Yes } & 377 & 75.2 \% \\ \text { No } & 124 & 24.8 \%\end{array}$

Had seen MSM STI patients in the last 12 months

$\begin{array}{ll}\text { Yes } & 267 \\ \end{array}$

No $\quad 234 \quad 46.7 \%$

Asked about sex with other men when seeing last patient

$\begin{array}{ll}\text { Yes } & 378 \\ & 75.4 \%\end{array}$

$\begin{array}{lll}\text { No } & 123 & 24.6 \%\end{array}$ 
Table 1 Demographic characteristics of physicians who saw at least one male STI patient, $2017(N=501)$ (Continued)

\begin{tabular}{lcl}
\hline \multicolumn{2}{l}{ Characteristics } & \multicolumn{1}{c}{ Total } \\
\cline { 2 - 3 } & $n$ & $\%$ \\
\hline Ask about anal sex when seeing last patient & \\
Yes & 277 & $55.3 \%$ \\
No & 224 & $44.7 \%$ \\
Recommended STI testing & d & when seeing last patient \\
Yes & 455 & $90.8 \%$ \\
No & 46 & $9.2 \%$ \\
\hline
\end{tabular}

${ }^{a}$ Associate's degree is usually earned in two years or more and can be attained at community colleges, technical colleges, vocational schools, and some colleges;

${ }^{\mathrm{b}}$ General medicine includes internal medicine, pediatrics and general practice; 'Others include Reproductive Medicine, Andrology, Emergence clinic, Hematology, Professional Health, AIDS Prevention Office;

${ }^{d}$ STI testing means both HIV testing and Syphilis testing

third $(n=77,29.2 \%)$ had neutral attitudes, and $11.6 \%$ $(n=33)$ had negative attitudes toward MSM.

\section{Physician interest in contributing to improving medical services for MSM}

When asked about interest in contributing to MSM clinical services, 59.5\% $(n=298)$ reported they were interested in having their medical institution names on a public clinic list capable of serving MSM, 61.3\% $(n=307)$ reported they were interested being on a public physician list capable of seeing MSM, and $68.1 \%(n=341)$ of physicians were interested in further training focused on clinical services for MSM.

\section{Factors associated with being an MSM-competent physician}

Among the 267 physicians who saw MSM STI patients, $60.3 \% \quad(n=161) \quad$ met criteria as MSM-competent physicians. Among those who did not meet criteria, most $(n=98,92.5 \%)$ failed to ask about anal sex with their patients. There were statistically significant differences between MSM-competent group with the non MSMcompetent group in terms of age, sex, education, and specialty (Table 3). As for the level and type of the medical institution, there was no difference between MSMcompetent and non-MSM-competent physicians. We did not observe any correlation between attitudes toward MSM and MSM-competency among physicians in our sample.

Medical institutions where free condoms and lubricants were available were more likely to have MSM-competent physicians $(\mathrm{aOR}=2.01,95 \% \mathrm{CI}: 1.21-3.34)$. This was true for medical institutions with STI pamphlets and educational material to have more MSM-competent physicians working there. Physicians who were more interested in contributing to activities to improve MSM clinical services were more likely to be MSM-competent. Activities included having their medical institution names on a public clinic list capable of serving MSM (aOR: 1.70, 95\%CI: 1.01-2.86), and being on a public physician list capable of serving MSM (aOR: 1.77, 95\%CI: 1.03-3.03).

\section{Discussion}

This study explores clinical competency and attitudes toward MSM among an online sample of physicians in China. This study contributes to the limited literature on clinical services for MSM in China by examining clinical competency in serving MSM patients and attitudes among physicians who see male STI patients. We found that most physicians reported asking about sexual orientation, recommending STI testing, and asking about anal intercourse in their last clinical encounters. We also found that most physicians were willing to attend MSM-focused clinical training and openly identify as physicians willing to see MSM.

Over 60\% of physicians who reported seeing MSM STI patients met basic criteria for MSM competency. Our results showed that the percentage of asking about same-sex sexual practices was higher than a previous study in China, which reported only $11 \%$ of the physicians asked their patients occasionally or most of the time [20]. The percentage of physicians asking about sexual practices is lower than that reported in high-income country studies focused on physicians who see patients with sexual health concerns $[33,34]$. In our study, nearly all physicians

Table 2 Physicians' attitudes towards male homosexuals in China, 2017 ( N=267)

\begin{tabular}{|c|c|c|c|}
\hline & Positive Attitudes & Neutral Attitudes & Negative Attitudes \\
\hline Statements & $n(\%)$ & $n(\%)$ & $n(\%)$ \\
\hline Overall & $158(59.2 \%)$ & $78(29.2 \%)$ & $31(11.6 \%)$ \\
\hline Male homosexuals are disgusting & $60(22.5 \%)$ & $180(67.4 \%)$ & $37(10.1 \%)$ \\
\hline Male homosexuality is a perversion & $77(28.8 \%)$ & $166(62.2 \%)$ & $24(9.0 \%)$ \\
\hline Homosexual behavior between two men is just plain wrong & $73(27.3 \%)$ & $155(58.1 \%)$ & $39(14.6 \%)$ \\
\hline Male homosexuality is merely a different kind of lifestyle that should not be condemned & $113(42.3 \%)$ & $124(46.5 \%)$ & $30(11.2 \%)$ \\
\hline $\begin{array}{l}\text { Male homosexuals should be segregated by society (residential segregation; occupational } \\
\text { segregation) }\end{array}$ & $147(55.1 \%)$ & $113(42.3 \%)$ & $7(2.6 \%)$ \\
\hline
\end{tabular}


Table 3 Factors associated with being a MSM-competent physician in China, 2017 ( $N=267)$

\begin{tabular}{|c|c|c|c|c|c|}
\hline & Overall ${ }^{\mathrm{a}}(n=267)$ & $\begin{array}{l}\text { MSM-competent } \\
\text { physicians }(n=161)\end{array}$ & $\begin{array}{l}\text { Non MSM-competent } \\
\text { physicians }(n=106)\end{array}$ & OR $(95 \% \mathrm{Cl})$ & $\mathrm{aOR} \mathrm{R}^{\mathrm{b}}(95 \% \mathrm{Cl})$ \\
\hline & $n(\%)$ & $n(\%)$ & $n(\%)$ & & \\
\hline \multicolumn{6}{|l|}{ Age (years) } \\
\hline$\leq 30$ & $55(20.6 \%)$ & $27(16.8 \%)$ & $28(26.4 \%)$ & Ref & \\
\hline $30-44$ & $127(47.6 \%)$ & $79(49.1 \%)$ & $48(45.3 \%)$ & $1.71(0.90-3.23)$ & \\
\hline$>44$ & $85(31.8 \%)$ & $55(34.2 \%)$ & $30(28.3 \%)$ & $1.90(0.95-3.79)$ & \\
\hline \multicolumn{6}{|l|}{ Sex } \\
\hline Male & 195(73.0\%) & $121(75.2 \%)$ & $74(69.8 \%)$ & $1.31(0.76-2.26)$ & \\
\hline Female & $72(27.0 \%)$ & $40(24.8 \%)$ & $32(30.2 \%)$ & Ref & \\
\hline \multicolumn{6}{|l|}{ Education } \\
\hline Associate's degree ${ }^{c}$ & $15(5.6 \%)$ & $10(6.2 \%)$ & $5(4.7 \%)$ & $2.00(0.56-7.10)$ & \\
\hline Bachelor's degree & $98(36.7 \%)$ & $62(38.5 \%)$ & $36(34.0 \%)$ & $1.72(0.78-3.79)$ & \\
\hline Master's degree & $120(44.9 \%)$ & $72(44.7 \%)$ & $48(45.3 \%)$ & $1.50(0.70-3.22)$ & \\
\hline PhD degree & $34(12.7 \%)$ & $17(10.6 \%)$ & $17(16.0 \%)$ & Ref & \\
\hline \multicolumn{6}{|l|}{ Specialty } \\
\hline Dermatovenerology & $109(40.8 \%)$ & $65(40.4 \%)$ & $44(42.3 \%)$ & $1.85(0.47-7.26)$ & \\
\hline Urology & $63(23.6 \%)$ & $41(25.5 \%)$ & $22(20.8 \%)$ & $2.33(0.57-9.57)$ & \\
\hline Proctology & $27(10.1 \%)$ & 19(11.8\%) & $8(7.5 \%)$ & $2.97(0.63-14.03)$ & \\
\hline General medicine $^{d}$ & $38(14.2 \%)$ & 16(9.9\%) & $22(20.8 \%)$ & $0.91(0.21-3.93)$ & \\
\hline Infectious Disease & $21(7.9 \%)$ & 16(9.9\%) & $5(4.7 \%)$ & $4.00(0.77-20.92)$ & \\
\hline Others $^{\mathrm{e}}$ & $9(3.4 \%)$ & $4(2.5 \%)$ & $5(4.7 \%)$ & Ref & \\
\hline \multicolumn{6}{|l|}{ Level of care } \\
\hline Primary & 13(4.9\%) & $8(5.0 \%)$ & $5(4.7 \%)$ & Ref & \\
\hline Secondary & $65(24.3 \%)$ & $33(20.5 \%)$ & $32(30.2 \%)$ & $0.65(0.19-2.18)$ & \\
\hline Tertiary & 189(70.8\%) & $120(74.5 \%)$ & $69(65.1 \%)$ & $1.09(0.34-3.45)$ & \\
\hline \multicolumn{6}{|l|}{ Type of Medical institute } \\
\hline Public & 238(89.1\%) & $145(90.1 \%)$ & $93(87.7 \%)$ & $1.27(0.58-2.76)$ & \\
\hline Private & $29(10.9 \%)$ & $16(9.9 \%)$ & $13(12.3 \%)$ & Ref & \\
\hline \multicolumn{6}{|c|}{ Proctoscope or anoscope available } \\
\hline Yes & $219(82.0 \%)$ & 138(85.7\%) & $81(76.4 \%)$ & $1.85(0.99-3.47)$ & \\
\hline No & $48(18.0 \%)$ & $23(14.3 \%)$ & $25(23.6 \%)$ & Ref & \\
\hline \multicolumn{6}{|c|}{ Free condom and lubricants available } \\
\hline Yes & $150(56.2 \%)$ & $101(62.7 \%)$ & $49(46.2 \%)$ & $1.96(1.19-3.22)^{* *}$ & $2.01(1.21-3.34)^{* *}$ \\
\hline No & $117(43.8 \%)$ & $60(37.3 \%)$ & $57(53.8 \%)$ & Ref & Ref \\
\hline \multicolumn{6}{|c|}{ STI prevention pamphlets or educational materials available } \\
\hline Yes & 208(77.9\%) & 138(85.7\%) & $70(66.0 \%)$ & $3.09(1.70-5.61)^{* * *}$ & $3.10(1.68-5.73)^{* * *}$ \\
\hline No & $59(22.1 \%)$ & $23(14.3 \%)$ & $36(34.0 \%)$ & Ref & Ref \\
\hline \multicolumn{6}{|c|}{ Interested in having medical institution name on the public clinic list capable of serving MSM } \\
\hline Yes & $174(65.2 \%)$ & $113(70.2 \%)$ & $61(57.5 \%)$ & $1.74(1.04-2.90)^{*}$ & $1.70(1.01-2.86)^{*}$ \\
\hline No & $93(34.8 \%)$ & $48(29.8 \%)$ & $45(42.5 \%)$ & Ref & Ref \\
\hline \multicolumn{6}{|c|}{ Interested in being on a public physician list capable of serving MSM } \\
\hline Yes & $182(68.2 \%)$ & $118(73.3 \%)$ & $64(60.4 \%)$ & $1.80(1.07-3.04)^{*}$ & $1.77(1.03-3.03)^{*}$ \\
\hline No & $85(31.8 \%)$ & $43(26.7 \%)$ & $42(39.6 \%)$ & Ref & Ref \\
\hline
\end{tabular}

Interested in further training focused on clinical services for MSM 
Table 3 Factors associated with being a MSM-competent physician in China, $2017(N=267)$ (Continued)

\begin{tabular}{|c|c|c|c|c|c|}
\hline & Overalla $^{a}(n=267)$ & $\begin{array}{l}\text { MSM-competent } \\
\text { physicians }(n=161)\end{array}$ & $\begin{array}{l}\text { Non MSM-competent } \\
\text { physicians }(n=106)\end{array}$ & OR (95\%Cl) & $\mathrm{aOR}^{\mathrm{b}}(95 \% \mathrm{Cl})$ \\
\hline & $n(\%)$ & $n(\%)$ & $n(\%)$ & & \\
\hline Yes & 194(72.7\%) & $123(76.4 \%)$ & $71(67.0 \%)$ & $1.60(0.93-2.75)$ & \\
\hline No & $73(27.3 \%)$ & $38(23.6 \%)$ & $35(33.0 \%)$ & Ref & \\
\hline Physicians' attitudes t & male homosexual & & & & \\
\hline Positive attitude & $157(58.8 \%)$ & $90(63.2 \%)$ & $67(55.9 \%)$ & Ref & \\
\hline Neutral attitude & $77(28.8 \%)$ & $50(25.5 \%)$ & $27(31.3 \%)$ & $1.38(0.78-2.43)$ & \\
\hline Negative attitude & $33(12.4 \%)$ & $21(11.3 \%)$ & $12(28.8 \%)$ & $1.30(0.60-2.83)$ & \\
\hline
\end{tabular}

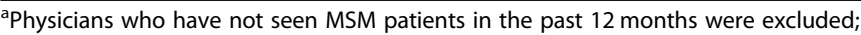

baOR controlled for age, sex, and education;

'Associate's degree is usually earned in two years or more and can be attained at community colleges, technical colleges, vocational schools, and some colleges;

${ }^{\mathrm{d} G e n e r a l}$ medicine includes internal medicine, pediatrics and general practice;

eOthers include Reproductive Medicine, Andrology, Emergence clinic, Hematology, Professional Health, AIDS Prevention Office;

${ }^{*} \mathrm{p}<0.05$; ${ }^{* *} p \leq 0.01 ;{ }^{* * *} p \leq 0.001$

reported recommending HIV/syphilis testing for their last STI patient. Although there are no comparable data for HIV testing among HIV/STI patients, research showed that a lower percentage of US physicians reported offering HIV testing. Among general practitioners in the US whose patients were general population, $41.7 \%$ of the physicians offered HIV testing [35]. Among HIV care providers whose patients were partly HIV infected, $60 \%$ routinely offered HIV testing to their patients [36]. Further studies should be conducted to investigate outcomes when physicians are seeing general patients and explore factors associated with patients accepting HIV testing offered by physicians in China.

MSM-competent physicians practiced in a wide range of clinical settings and medical subspecialties. Although some studies have found higher quality STI care in subspecialist clinics [37, 38], we did not observe significant differences in MSM competency between subspecialists and general practitioners. Additionally, MSM-competent physicians were associated with institutional factors (providing condom, lubricants, STI prevention pamphlets or educational materials), rather than individual factors. Recommendations of educational materials are recommended in guidelines for HIV prevention and LGBT patients, reinforcing the office-based education effect [39]. Guidelines for care of LGBT patients state that LGBT patients often find clues to determine what information they are comfortable to share with health care providers [40]. The educational and prevention material may have a potential effect on the interaction between physicians and STI patients. In addition, these materials may be the results of the institutional support for sexual health issues and risk population, which have a positive effect on physicians' competency. Provision of educational and prevention material can play a useful role in an MSM competency improvement program.
Physician clinical competency and attitudes are both critical toward engaging MSM in care. In our study, most physicians reported positive attitudes towards MSM, although based on individual statement alone, most physicians reported neutral attitudes. Our finding contrasts with previous Chinese research from 1101 physicians showing negative physician attitudes toward MSM and widespread discrimination [41]. The more inclusive societal attitudes towards LGBT population showed from a recent national survey may influence health providers' attitudes [42]. We found no correlation between the physicians' MSM competency and attitudes towards MSM, indicating the disjunction between clinical practice and personal attitudes. However, it is the practical competency and non-judgmental attitude that work together to optimize MSM's well-being. Physicians in China need both training to improve clinical practice and reduce stigma to better serve the MSM population.

We also found that most physicians were willing to receive further training to better serve MSM. Training and education initiatives to improve knowledge, attitudes, and clinical competencies among physicians for serving MSM patients is essential to improving the health of sexual minorities [43]. In LMICs, increased capacity from training in providing non-stigmatizing and non-discriminatory services to MSM patients can improve clinical outcomes [44, 45]. The high interest in our study suggests that subsequent MSM training may be feasible. Further research is needed to find the effect of training interventions or programs for physicians to improve their clinical practice and attitudes towards MSM.

The study has several limitations. First, the study was based on physician self-report, introducing the potential for social desirability and recall bias [46]. Physicians were asked about their last patients to reduce the likelihood of the recall bias, but responses 
related to competent clinical practice and willingness to contribute to MSM services might be over reported due to the social desirability bias. However, self-report surveys have been widely used in the studies with physicians [33, 34, 37, 47], allowing a reasonable comparison to the literature. Second, we used a narrow definition of MSM-competency that focuses on physicians' clinical practice. Another limitation of the definition is the lack of patients' voice and experience of the competency. Third, we did not assess whether the last clinical encounter was a new patient or an established patient, which may also influence physician behaviors. For established patient, physicians may have known the sexual history, so they did not need to ask these questions again in their last encounter. In this case, it would not necessarily indicate they are not competent. Forth, physicians were recruited from a medical app online, and there may be selection bias because all survey participants were app users. Fifth, this was a cross-sectional study, so no causal relationship can be established. Sixth, we didn't obtain the information on how the STIs were confirmed by physicians. There was a potential for invalidity of STI diagnosis.

\section{Conclusions}

This study expands the limited literature on MSM service providers in China, providing a current perspective of MSM-competent physicians. We observed a diverse sample of physicians from a range of subspecialties and medical institutions in China meeting criteria for competent clinical care for MSM. Most physicians were interested in the training and improving MSM clinical services. More research on physicians' clinical competency is strongly recommended to provide a more accurate and comprehensive description of MSM-competency. Further research is needed to explore novel methods of engaging physicians in MSM care and developing interventions aimed at physicians in order to improve MSM clinical competency.

\section{Abbreviations \\ App: Mobile phone application; HIV: human immunodeficiency virus; LMICs: Low- and middle-income countries; MSM: Men who have sex with men; STI: Sexually transmitted infection}

\section{Acknowledgements}

The authors would like to thank all the participants and express the gratitude to the staff members of Social Entrepreneurship to Spur Health (SESH) for their help in the crowdsourcing. We would also thank Xingren App Company for broadcasting the recruitment advertisement via their platform.

\section{Funding}

This research was supported by Shenzhen Healthcare Research Project (No. SZFZ2017024), the National Institutes of Health (NIAID 1R01Al114310), and the UNC-South China STD Research Training Center (FIC 1D43TW009532). The funders played no role in any part of the study.

\section{Availability of data and materials}

The datasets used and/or analyzed during the current study are available from the corresponding author on reasonable request.

\section{Authors' contributions}

JT and ZL designed the study and survey. PZ and BC conducted the study, collected and interpreted the data. PZ, BC and CB together drafted the manuscript. JT, ZL, WT, JO, YD and WC helped to conduct the survey and participated in critical revision of the manuscript. All authors read and approved the final manuscript.

\section{Ethics approval and consent to participate}

The institutional review board of Nanshan Center of Chronic Disease Control, Shenzhen, China provided approval for this study. The IRB code of the study is $\| 20170016$. All participants signed the electronic consent form before starting the survey.

\section{Consent for publication}

Not applicable.

\section{Competing interests}

The authors declare that they have no competing interests.

\section{Publisher's Note}

Springer Nature remains neutral with regard to jurisdictional claims in published maps and institutional affiliations.

\section{Author details \\ ${ }^{1}$ Shenzhen Nanshan Center for Chronic Disease Control, Shenzhen, China. ${ }^{2}$ School of Media and Communication, Shenzhen University, Nanshan Block Huaming Road, 7, Shenzhen 518052, China. ${ }^{3}$ University of North Carolina Project-China, No. 2 Lujing Road, Guangzhou 510095, China. ${ }^{4}$ School of Medicine, University of North Carolina at Chapel Hill, North, Carolina, USA. ${ }^{5}$ Faculty of Infectious and Tropical Diseases, London School of Hygiene and Tropical Medicine, London, UK. ${ }^{6}$ Central Clinical School, Monash University, Melbourne, Australia.}

Received: 13 July 2018 Accepted: 29 November 2018

Published online: 13 December 2018

\section{References}

1. Wheeler J, Anfinson K, Valvert D, Lungo S. Is violence associated with increased risk behavior among MSM? Evidence from a population-based survey conducted across nine cities in Central America. Glob Health Action. 2014;7:24814.

2. Zahn R, Grosso A, Scheibe A, Bekker LG, Ketende S, Dausab F, et al. Human rights violations among men who have sex with men in southern Africa: comparisons between legal contexts. PLoS One. 2016;11:e0147156.

3. Mgopa LR, Mbwambo J, Likindikoki S, Pallangyo P. Violence and depression among men who have sex with men in Tanzania. BMC Psychiatry. 2017;17:296

4. Sandfort TGM, Knox JR, Alcala C, El-bassel N, Kuo I, Smith LR. Substance use and Hiv risk among men who have sex with men in Africa: a systematic review. Jaids J Acquir Immune Defic Syndr. 2017;76:e34-46. https://doi.org/ 10.1097/qai.0000000000001462.

5. Centers for Disease Control and Prevention. HIV and Young Men Who Have Sex With Men. 2014

6. Wirtz AL, Kamba D, Jumbe V, Trapence G, Gubin R, Umar E, et al. A qualitative assessment of health seeking practices among and provision practices for men who have sex with men in Malawi. BMC Int Health Hum Rights. 2014;14:20. https://doi.org/10.1186/1472-698X-14-20.

7. Risher K, Adams D, Sithole B, Ketende S, Kennedy C, Mnisi Z, et al. Sexual stigma and discrimination as barriers to seeking appropriate healthcare among men who have sex with men in Swaziland. J Int AIDS Soc. 2013; 16(Suppl 2):18715.

8. Kennedy CE, Baral SD, Fielding-Miller R, Adams D, Dludlu P, Sithole B, et al. "They are human beings, they are Swazi": intersecting stigmas and the positive health, dignity and prevention needs of HIV-positive men who have sex with men in Swaziland. J Int AIDS Soc. 2013;16(Suppl 3):18749.

9. Kushwaha S, Lalani Y, Maina G, Ogunbajo A, Wilton L, Agyarko-Poku T, et al. "But the moment they find out that you are MSM...": a qualitative 
investigation of HIV prevention experiences among men who have sex with men (MSM) in Ghana's health care system. BMC Public Health. 2017;17:770. https://doi.org/10.1186/s12889-017-4799-1.

10. Tang S, Tang W, Meyers K, Chan P, Chen Z, Tucker JD. HIV epidemiology and responses among men who have sex with men and transgender individuals in China: a scoping review. BMC Infect Dis. 2016;16:588. https:// doi.org/10.1186/s12879-016-1904-5.

11. Zou H, Hu N, Xin Q, Beck J. Hiv testing among men who have sex with men in China: a systematic review and meta-analysis. AIDS Behav. 2012;16: 1717-28.

12. Chow EPF, Tucker JD, Wong FY, Nehl EJ, Wang Y, Zhuang $X$, et al. Disparities and risks of sexually transmissible infections among men who have sex with men in China: a meta-analysis and data synthesis. PLoS One. 2014;9:e89959. https://doi.org/10.1371/journal.pone.0089959.

13. Wu Z, Xu J, Liu E, Mao Y, Xiao Y, Sun X, et al. HIV and syphilis prevalence among men who have sex with men: a cross-sectional survey of 61 cities in China. Clin Infect Dis. 2013;57:298-309.

14. Liu Y, Sun X, Qian H-Z, Yin L, Yan Z, Wang L, et al. Qualitative assessment of barriers and facilitators of access to HIV testing among men who have sex with men in China. AIDS Patient Care STDs. 2015;29:481-9. https://doi.org/ 10.1089/apc.2015.0083.

15. Feng $Y$, Wu Z, Detels R. Evolution of men who have sex with men community and experienced stigma among men who have sex with men in Chengdu, China. J Acquir Immune Defic Syndr. 2010;53(Suppl 1):S98-103. https://doi.org/10.1097/QAl.0b013e3181c7df71.

16. Tang W, Mao J, Tang S, Liu C, Mollan K, Cao B, et al. Disclosure of sexual orientation to health professionals in China: results from an online crosssectional study. J Int AIDS Soc. 2017;20:21416.

17. Stupiansky NW, Liau A, Rosenberger J, Rosenthal SL, Tu W, Xiao S, et al. Young Men's disclosure of same sex behaviors to healthcare providers and the impact on health: results from a US National Sample of young men who have sex with men. AIDS Patient Care STDs. 2017;31:342-7. https://doi. org/10.1089/apc.2017.0011.

18. Callander D, Bourne C, Pell C, Finlayson R, Forssman B, Baker D, et al. Recording the sexual orientation of male patients attending general practice. Fam Pract. 2015:32:35-40.

19. Kennedy CE, Fonner VA, Sweat MD, Okero FA, Baggaley R, O'Reilly KR. Provider-initiated HIV testing and counseling in low- and middle-income countries: a systematic review. AIDS Behav. 2013;17:1571-90.

20. Tucker JD, Walensky RP, Yang LG, Yang B, Bangsberg DR, Chen XS, et al. Expanding provider-initiated HIV testing at STI clinics in China. AIDS Care. 2012;24:1316-9. https://doi.org/10.1080/09540121.2012.661835.

21. Makadon HJ, Mayer HK, Potter J, Goldhammer H. The Fenway guide to lesbian, gay, bisexual, and Transgender Health; 2015.

22. Bien CH, Muessig KE, Lee R, Lo EJ, Yang LG, Yang B, et al. HIV and syphilis testing preferences among men who have sex with men in South China: a qualitative analysis to inform sexual health services. PLoS One. 2015;10: e0124161. https://doi.org/10.1371/journal.pone.0124161.

23. Taegtmeyer M, Davies A, Mwangome M, van der Elst EM, Graham SM, Price MA, et al. Challenges in providing counselling to MSM in highly stigmatized contexts: results of a qualitative study from Kenya. PLoS One. 2013;8:e64527.

24. European Centre for Disease Prevention and Control. HIV and STI prevention among men who have sex with men. European Centre for Disease Prevention and Control; 2015. https://doi.org/10.2900/66666.

25. Watson J, Tang W, Pan SW, Wu DD, Zhao P, Cao B, et al. Out of the closet, into the clinic: opportunities for expanding MSM-competent Services in China. Sex Transm Dis. 2018;45:527-33. https://doi.org/10.1097/OLQ. 0000000000000808

26. Wang Q, Liu Q, Xu J. Sexual Transmitted Disease Clinical Diagnosis and Prevention Guideline. China CDC: National Center for STD control; 2014.

27. Xu Z, Zhao Y, Xu B, Zhu D, Li H. Research on online medical consultation from the Physician's perspective. Wirel Internet Technol. 2015;23:119-20.

28. Bourne C. Clinical guideline for sexual health Care of men who have sex with men and transgender; 2011.

29. Famliy Health International. Guidelines and Standards for Counseling HighRisk Groups IN Clinic Settings. 2011.

30. Guidance P, Collaborative FOR. Implementing comprehensive HIV-STI programmes MSM. 2014. http://www.unfpa.org/sites/default/files/pub-pdf/ MSMIT_for_Web.pdf

31. Herek GM. Heterosexuals' attitudes toward lesbians and gay men: correlates and gender differences. J Sex Res. 1988;25:451-77.
32. Yu Y, Xiao S, Xiang Y. Application and testing the reliability and validity of a modified version of herek's attitudes toward lesbians and gay men scale in China. J Homosex. 2011;58:263-74.

33. Lanier Y, Castellanos T, Barrow RY, Jordan WC, Caine V, Sutton MY. Brief sexual histories and routine HIV/STD testing by medical providers. AIDS Patient Care STDs. 2014;28:113-20. https://doi.org/10.1089/apc.2013.0328.

34. Wimberly YH, Hogben M, Moore-Ruffin J, Moore SE, Fry-Johnson Y. Sexual history-taking among primary care physicians. J Natl Med Assoc. 2006;98:1924-9.

35. McNaghten AD, Valverde EE, Blair JM, Johnson CH, Freedman MS, Sullivan PS. Routine HIV testing among providers of HIV Care in the United States, 2009. PLoS One. 2013;8:e51231.

36. Zielinski M, Leung SJ, Akkaya-hocagil T, Rowe KA, Ortega-peluso C, Smith LC. Correlates of Routine HIV Testing Practices. A Survey of New York State Primary Care Physicians. 2011;2015(68 suppl 1):S21-9.

37. Asch SM, Sa'adah MG, Lopez R, Kokkinis A, Richwald GA, Rhew DC. Comparing quality of care for sexually transmitted diseases in specialized and general clinics. Public Health Rep. 2002;117:157-63.

38. Voeten HA, Otido JM, O'Hara HB, Kuperus AG, Borsboom GJ, Ndinya-Achola $J \mathrm{O}$, et al. Quality of sexually transmitted disease case management in Nairobi, Kenya: a comparison among different types of healthcare facilities. Sex Transm Dis. 2001;28:633-42 http://ovidsp.ovid.com/ovidweb.cgi?T= JS\&PAGE $=$ reference\&D=med4\&NEWS $=\mathrm{N} \& A N=11677385$.

39. Workowski KA, Bolan GA. Sexually Transmitted Diseases Treatment Guidelines. MMWR Recomm reports. 2015;64(RR3):1-137. https://doi.org/10. 1097/00008480-200308000-00006.

40. Gay and Lesbian Medical Association. Guidelines for Care of Lesbian, Gay, Bisexual, and transgender patients. Environment. 2006. http://www.qahc.org. au/files/shared/docs/GLMA_guide.pdf.

41. Li L, Liang L-J, Wu Z, Lin C, Wen Y. Individual attitudes and perceived social norms: reports on HIV/ AIDS-related stigma among service providers in China. Int J Psychol. 2009:44:443-50.

42. United Nation Development Programme. Being LGBTI in China: a National Survey on social attitudes towards sexual orientation, gender identity and gender expression. 2016. http://www.cn.undp.org/content/china/en/home/ library/democratic governance/being-lgbt-in-china.html.

43. Sekoni AO, Gale NK, Manga-Atangana B, Bhadhuri A, Jolly K. The effects of educational curricula and training on LGBT-specific health issues for healthcare students and professionals: a mixed-method systematic review. J Int AIDS Soc. 2017;20:21624. https://doi.org/10.7448/IAS.20.1.21624.

44. Gu J, Lau JTF, Wang Z, Wu AMS, Tan X. Perceived empathy of service providers mediates the association between perceived discrimination and behavioral intention to take up HIV antibody testing again among men who have sex with men. PLoS One. 2015;10:e0117376. https://doi.org/10. 1371/journal.pone.0117376.

45. Micheni M, Kombo BK, Secor A, Simoni JM, Operario D, van der Elst EM, et al. Health provider views on improving antiretroviral therapy adherence among men who have sex with men in coastal Kenya. AIDS Patient Care STDs. 2017:31:113-21. https://doi.org/10.1089/apc.2016.0213.

46. Montaño DE, Phillips WR. Cancer screening by primary care physicians: a comparison of rates obtained from physician self-report, patient survey, and chart audit. Am J Public Health. 1995;85:795-800. https://doi.org/10.2105/AJPH.85.6.795.

47. St. Lawrence JS, Montaño DE, Kasprzyk D, Phillips WR, Armstrong K, Leichliter JS. STD screening, testing, case reporting, and clinical and partner notification practices: a national survey of US physicians. Am J Public Health. 2002:92:1784-8

\section{Ready to submit your research? Choose BMC and benefit from:}

- fast, convenient online submission

- thorough peer review by experienced researchers in your field

- rapid publication on acceptance

- support for research data, including large and complex data types

- gold Open Access which fosters wider collaboration and increased citations

- maximum visibility for your research: over $100 \mathrm{M}$ website views per year

At $\mathrm{BMC}$, research is always in progress.

Learn more biomedcentral.com/submissions 